\title{
Single Center Experience in Vascular and Endovascular Surgery during the COVID-19 Pandemic: Walking on the Icy Road
}

Görkem Yiğit

Department of Cardiovascular Surgery, Yozgat State Hospital, Yozgat, TURKEY

Corresponding Author: Görkem Yiğit, Department of Cardiovascular Surgery, Yozgat State Hospital, Yozgat, TURKEY

Received Date: April 22, 2021; Accepted Date: April 27, 2021; Published Date: May 03,2021

Citation: Görkem Yiğit (2021) Single Center Experience in Vascular and Endovascular Surgery during the COVID-19 Pandemic: Walking on the Icy Road. J. Clinical Cardiology and Cardiovascular Interventions, 4(9); Doi:10.31579/2641-0419/170

Copyright: (c) 2021 Görkem Yiğit, This is an open-access article distributed under the terms of the Creative Commons Attribution License, which permits unrestricted use, distribution, and reproduction in any medium, provided the original author and source are credited.

Background: Along with other areas of specialization, the cardiovascular surgery clinic is a department that
has a significant contribution to the COVID-19 pandemic process with both the management of vascular
emergencies and the rapid and effective use of interventional methods. This study aims to present endovascular
and open vascular surgical procedures performed in single center between March 2020 and December 2020
during the ongoing pandemic.
Materials and methods: A total of 230 patients underwent open surgery 60 patients and endovascular /
interventional treatment 170 patients by the Cardiovascular Surgery clinic were included in the study. It was
aimed to determine the procedural details of the patients, follow-up results, complications and mortality rates.
The compatibility of the variables to normal distribution was examined using visual and analytical methods.
The Shapiro-Wilk test was used to check the normal distribution of continuous variables.
Results: In the open vascular surgery group, the mean age was $51.4 \pm 23.2$ years (range $12-90$ years). Sixteen
(26.7\%) patients were female and 44 ( $73.3 \%$ ) male. The median follow-up from the time of the open vascular
procedure was $4.3 \pm 1.2$ months. There were ten (16.7\%) minor complications. There were five deaths after
procedures. In the endovascular / interventional group, the mean age was $58.5 \pm 18.6$ years (range $18-94$ years).
Ninety one (53.5\%) patients were female and 79 (46.5\%) male. The median follow-up from the time of the
drug-eluting balloon angioplasty and pharmacomechanical thrombectomy patients were $4.0 \pm 1.1$ months. There
were thirty four (20\%) minor complications and two deaths after procedures.
Conclusion: Our experience and successful results shows how surgical and interventional procedures
participated in the care of hospitalized COVID-19 patients during the height of the coronavirus pandemic. large
number of patients with previous resistant left atrial thrombus with and secure since the low adverse event rates.
Key words: coronavirus disease 2019 ; embolectomy; traumatic vascular injury; vascular surgery;
endovascular surgery

\section{Introduction}

The pandemic spread of the novel coronavirus (SARS-CoV-2; COVID-19) has seriously affected the delivery of health care services around the world. [1] Patients who are hospitalized, respiratory and renal insufficency can be seen in addition to cardiac damage due to venous and arterial thromboembolism in severe COVID-19 disease. [2]

Along with other areas of specialization, the cardiovascular surgery clinic is a department that has a significant contribution to the pandemic process with both the management of vascular emergencies and the rapid and effective use of interventional methods. In this period, cardiovascular surgeons and interventional radiologists can place tunneled-cuffed or temporary hemodialysis catheters in patients with COVID-19 who develop renal failure, as per their experience. [3] Besides this, acute limb ischemia and major traumatic vascular injuries are significant vascular emergencies that require fastly and early intervention, resulting in functional deficit, limb loss, and even death. [4] Moreover, in selected patients with proximal deep vein thrombosis (DVT), pharmacomechanical thrombectomy (PMT) and catheter-directed thrombolysis can be performed in terms of life-threatening venous thromboembolism (VTE). [5]
This study aims to present endovascular and open vascular surgical procedures performed in single center between March 2020 and December 2020 during the ongoing pandemic.

\section{Material and methods Study Design}

During the pandemic period between March 2020 and December 2020, 300 patients who underwent open surgery due to vascular injuries and acute embolism or endovascular / interventional treatment due to hemodialysis (HD) catheter placement, pharmacomechanical thrombectomy for deep venous thrombosis and chronic critic leg ischemia by the Cardiovascular Surgery clinic were screened. Data were retrieved from the electronic patient's records. Patients who were taken to elective surgery, had incomplete information in their files, and did not agree to participate in the study protocol were excluded from the study.

Finally, a total of 230 patients who underwent vascular surgery or endovascular treatment

were included. There were 60 patients in the vascular surgery group and 170 patients in the interventional treatment group. The patients in the vascular surgery group were evaluated retrospectively in terms of accompanying 
comorbid diseases, injury sites, type of anesthesia, surgical procedure, operation time, complications, intensive care and hospital stay and followup results. [4,6] The patients in the interventional group were evaluated retrospectively in terms of comorbid diseases, type of interventional or endovascular treatments, duration of procedure, type of anesthesia, and complications. [7] The demographic data and procedural details of both groups are shown in Table 1 and Table 2.

\section{Open vascular procedures}

In patients who were evaluated as an outpatient clinic by cardiovascular surgery, the patient's history and physical examination revealed that the presence of pulse deficit, coldness, cyanosis, uncontrollable or pulsatile bleeding at the injury site, enlarged or large hematoma, murmur or trill were interpreted as vascular injury findings. [4] The rapid COVID-19 PCR swab test was taken in patients who were diagnosed quickly, without the need for advanced diagnostic methods, and after the patient was taken into operation. Blood and blood products have been used in multi-trauma patients with excessive blood loss and haemodynamic instability. In addition, the operations were carried out simultaneously with other surgical specialists.

Patients who presented with limb pain, pallor, coldness, and discoloration and who were found to have an appearance consistent with acute embolism as a result of contrast-enhanced extremity computed tomography (CT) angiography were taken into emergency surgery. [4] Simultaneously, high resolution Thorax CT imaging was performed and rapid COVID-19 PCR swab test was taken for all patients.

General $(61.7 \%)$ and local anesthesia $(38.3 \%)$ was preferred in patients undergoing open surgery. After the hemodynamic stabilization of the patients was achieved, if there was no contraindication, $100 \mathrm{U} / \mathrm{kg}$ heparin IV bolus was given before placing the vascular clamp. [4] Subsequently, the proximal and distal ends of the injured vascular structures were determined visually, and if necessary, thrombectomy was performed first with a Fogarty catheter. Primary repair or saphenous vein graft interposition is aimed in the anastomosis in order to ensure the continuity of the vascular structures and optimum circulation. No ligation was performed in any vascular injury patient. Tetanus prophylaxis was administered to all patients presenting with vascular injury or acute limb embolism in the emergency department. After the operation, antibiotherapy and low molecular weight heparin were started during their hospitalization. [4,6] In addition, the necessary medications were added to the patients whose COVID-19 PCR test was positive. Later, the follow-up of the patients was continued with the infection and microbiology physician. In the presence of other accompanying tissue and organ injuries, the relevant branch physician was enabled to participate in the operation and the patient was followed up together.

\section{Endovascular and interventional procedures}

In the interventional group, COVID-19 PCR swab samples were obtained from all patients. If the patients were diagnosed with acute renal failure (ARF) during outpatient or ward follow-ups, a temporary hemodialysis (HD) catheter was placed under local anesthesia and under sterile conditions at the bedside or in the outpatient operating room. [7] A bedside temporary HD catheter was placed in patients who developed ARF during intensive care unit follow-ups. Permanent tunneled HD catheter was placed in the operating room under fluoroscopy and under local anesthesia in patients who developed chronic renal failure (CRF) and needed long-term dialysis.
Permanent tunneled HD catheters were placed in the internal jugular vein in 20 patients and femoral vein in 2 patients using the standard Seldinger method.

Besides, symptomatic cases involving the lower extremity iliac veins and presenting within 14 days were hospitalized by starting low molecular weight heparin. Then, in the angiography unit under local anesthesia, the vena cava inferior filter was placed from the contralateral leg, and pharmacomechanical thrombectomy and catheter-mediated thrombolysis was performed from the occluded leg. Afterwards, oral anticoagulation was continued and they were discharged.

Appropriate patients who did not have acute ischemia, were followed up with maximal medical therapy from the outpatient clinic and had intermittent claudication with resting pain were hospitalized. Subsequently, digital subtraction angiography (DSA) imaging and drug-eluting balloon angioplasty (DEB) / stent procedures were performed on these patients in our angiography unit. Prior to PTA, all patients were evaluated with Duplex ultrasound and DSA. In the clinical practice of our department, PTAs are performed under local anesthesia with monitorization by cardiovascular surgeons in the hybrid operating theater. [8] We usually prefer antegrade femoral or contralateral retrograde femoral access. Following the insertion of a 7-Fr single lumen sheath, intravenous heparin is administered according to an activated clotting time (ACT) of 180 to $200 \mathrm{sec}$. [8] All lesions are dilated with PCB (at a vessel/balloon ratio of $1: 1$ on the basis of visual estimate) for a total inflation time of $3 \mathrm{~min}$ at 6 to $14 \mathrm{~atm}$. Balloons are inflated only once. However, when control angiography reveals a residual lesion ( $>50 \%$ stenosis), flow-limiting dissection or atherosclerotic plaque deformation, a second PCB is carried out and dilatation is maintained for a longer period ( $\geq 3 \mathrm{~min}$ ). In such cases in which residual stenosis or flowlimiting dissection persists after repeated dilatation, self-expanding nitinol stents are implanted as bail-out therapy. [8]

This retrospective study has been conducted in accordance with the principles of the Helsinki Declaration and approved by the Yozgat State Hospital and Yozgat Provincial Health Directorate Commitee (Date: 21.12.2020, No: 92198657-000-7080).

\section{Data Analysis}

All statistical analysis was performed using the SPSS version 21.0 software (SPSS Inc., Chicago, IL, USA). Descriptive data were expressed in mean \pm standard deviation (SD) or median (min-max) for continuous variables and in number and frequency for nominal variables. The compatibility of the variables to normal distribution was examined using visual (histogram) and analytical methods (Kolmogorov-Smirnov / Shapiro-Wilk Tests). The Shapiro-Wilk test was used to check the normal distribution of continuous variables. A p value of $<0.05$ was considered statistically significant. The graphs are edited with the GraphPad Prism version 8.0.3 (GraphPad Software, La Jolla, CA, USA) software.

\section{Results}

Among the 230 patients hospitalized during the pandemic period between March 2020 and December 2020, there were 60 (26.1\%) patients underwent open vascular procedures and $170(73.9 \%)$ patients endovascular / interventional treatment. Demographic characteristics and procedural details of the patients in vascular surgical group was shown in Table 1. 


\begin{tabular}{|c|c|c|}
\hline \multicolumn{2}{|l|}{ Data } & Open vascular group, $n=60, \%$ \\
\hline \multicolumn{2}{|l|}{ Age } & 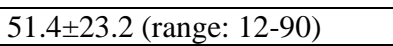 \\
\hline Sex & $\begin{array}{l}\text { Male } \\
\text { Female }\end{array}$ & $\begin{array}{l}44(73.3 \%) \\
16(26.7 \%) \\
\end{array}$ \\
\hline \multirow[t]{2}{*}{ Procedures } & $\begin{array}{l}\text {-Embolectomy } \\
\text { Femoral Embolectomy } \\
\text { Brachial Embolectomy }\end{array}$ & $\begin{array}{l}24(40 \%) \\
15(25 \%) \\
9(15 \%)\end{array}$ \\
\hline & $\begin{array}{l}\text {-Vascular Repair Anastomosis } \\
\text { End-to-end Radial Artery } \\
\text { End-to-end Brachial Artery } \\
\text { End-to-end Ulnar Artery } \\
\text { End-to-end Posterior Tibial Artery } \\
\text { End-to-end Femoral Artery } \\
\text { End-to-end Popliteal Artery } \\
\text { Saphenous Vein Bypass Radial Artery } \\
\text { Saphenous Vein Bypass Popliteal } \\
\text { Artery } \\
\text {-Carotid Endarterectomy }\end{array}$ & $\begin{array}{l}33(55 \%) \\
9(15 \%) \\
7(11.7 \%) \\
7(11.7 \%) \\
3(5 \%) \\
2(3.3 \%) \\
2(3.3 \%) \\
2(3.3 \%) \\
1(1.7 \%) \\
3(5 \%)\end{array}$ \\
\hline Comorbidity & $\begin{array}{l}\text { Hypertension } \\
\text { Diabetes Mellitus } \\
\text { Chronic Obstructive Pulmonary } \\
\text { Disease }\end{array}$ & $\begin{array}{l}14(23.3 \%) \\
8(13.3 \%) \\
8(13.3 \%)\end{array}$ \\
\hline \multicolumn{2}{|c|}{ Procedure time } & Median 67 (Q1:50-Q3:119) \\
\hline \multicolumn{2}{|c|}{ Follow-up (month) } & $4.3 \pm 1.2$ \\
\hline \multicolumn{2}{|c|}{ ICU stay (day) } & Median $1(\min 1-\max 5)$ \\
\hline \multicolumn{2}{|c|}{ Hospital length of stay (day) } & Median $6(\min 3-\max 18)$ \\
\hline Anesthesia type & $\begin{array}{l}\text { General } \\
\text { Local }\end{array}$ & $\begin{array}{l}37(61.7 \%) \\
23(38.3 \%)\end{array}$ \\
\hline Procedure side & $\begin{array}{l}\text { Right } \\
\text { Left }\end{array}$ & $\begin{array}{l}32(53.3 \%) \\
28(46.7 \%)\end{array}$ \\
\hline Complications & $\begin{array}{l}\text { Hematoma } \\
\text { Bleeding } \\
\text { Wound Infection }\end{array}$ & $\begin{array}{l}2(3.3 \%) \\
3(5 \%) \\
5(8.3 \%) \\
\end{array}$ \\
\hline \multicolumn{2}{|l|}{ Mortality } & $5(8.3 \%)$ \\
\hline
\end{tabular}

Open vascular surgical procedures were performed utilizing general anesthesia in $37(61.7 \%)$ patients, mild sedation and local anesthetic only in $23(38.3 \%)$. The median length of intensive care unit (ICU) stay was 1 day (range 1-5 days). The median length of hospitalization was 6 days (range 318 days). The median follow-up from the time of the open vascular procedure was $4.3 \pm 1.2$ months. There were ten $(16.7 \%)$ minor complications. There were five deaths after procedures. Four patients in embolectomy group

\begin{tabular}{|l|l|l|}
\hline \multicolumn{2}{|l|}{ Data } & Endovascular group, $\mathrm{n}=170, \%$ \\
\hline Age & Male & $58.5 \pm 18.6$ (range: $18-94)$ \\
\hline Sex & Female & $79(46.5 \%)$ \\
& Temporary HD catheter & $91(53.5 \%)$ \\
\hline Procedures & Permanent tunneled HD catheter & $119(70 \%)$ \\
& Drug-eluting balloon angioplasty & $22(12.9 \%)$ \\
& Pharmacomechanical thrombectomy & $9(5.3 \%)$ \\
& & \\
\hline
\end{tabular}

because of older ages and severe COVID-19 pneumonia. One patient was admitted with a gunshot injury, severe hemodynamic impairment and major bleeding, and the saphenous vein bypass was applied to the popliteal artery, but the patient died in the intensive care follow-up.

Demographic characteristics and procedural details of the patients in endovascular / interventional group was shown in Table 2. 


\begin{tabular}{|l|l|l|}
\hline Comorbidity & Acute Renal Failure & $104(61.1 \%)$ \\
& Chronic Renal Failure & $37(21.7 \%)$ \\
& Hypertension & $36(21.2 \%)$ \\
& Diabetes Mellitus & $20(11.8 \%)$ \\
& Chronic Obstructive Pulmonary & $18(10.6 \%)$ \\
& Disease & \\
& & \\
\hline Procedure time & Median 30 (Q1:10-Q3:60) \\
\hline Follow-up (month) & $4.0 \pm 1.1$ \\
\hline ICU stay (day) & Median 0 (min 0- max 5) \\
\hline Hospital length of stay (day) & Median 2 (min 3- max 10) \\
\hline Anesthesia & General & $2(1.2 \%)$ \\
type & Local & $168(98.8 \%)$ \\
\hline Procedure side & Right & $128(75.3 \%)$ \\
& Left & $42(24.7 \%)$ \\
\hline Complications & Hematoma & $25(14.7 \%)$ \\
& Bleeding & $7(4.1 \%)$ \\
& Wound Infection & $1(0.6 \%)$ \\
& Pseudoaneurysm & $1(0.6 \%)$ \\
\hline Mortality & & $2(1.2 \%)$ \\
\hline
\end{tabular}

Table 2: Demographic characteristics and procedural details of the patients in endovascular / interventional group.

Bedside procedures included placement of tunneled or temporary HD catheter. Other procedures were performed in the angiography unit. Endovascular / interventional vascular procedures procedures were performed utilizing general anesthesia in $2(1.2 \%)$ patients, local anesthetic only in 168 (98.8\%). The median length of hospitalization in drug-eluting balloon angioplasty and pharmacomechanical thrombectomy patients were 2 days (range 3-10 days). The median follow-up from the time of the drugeluting balloon angioplasty and pharmacomechanical thrombectomy patients were $4.0 \pm 1.1$ months. There were thirty four (20\%) minor complications. There were two deaths after procedures. One patient who underwent pharmacomechanic thrombectomy for DVT died after cardiac arrest due to pulmonary embolism. The other patient died because of older age and severe COVID-19 pneumonia in the ICU unit.

Also, procedural details of the patients in both groups were shown in Graphic 1 and 2.

\section{Vascular Surgical Procedures}

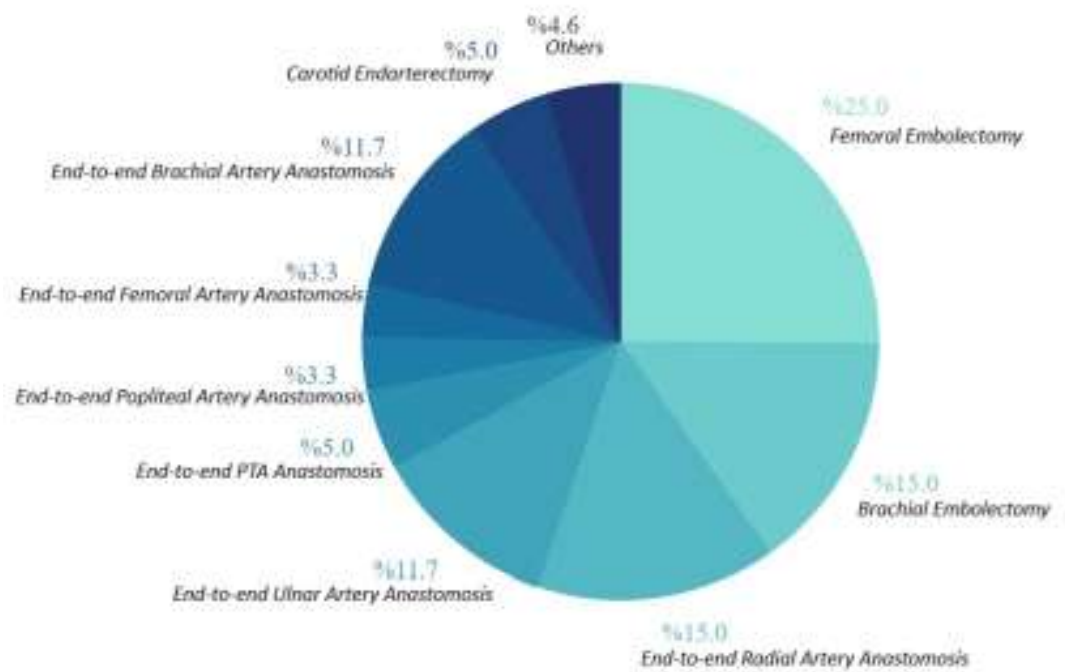

Graphic 1: Vascular surgical procedural details of the patients. 


\section{Endovascular / Interventional Procedures}

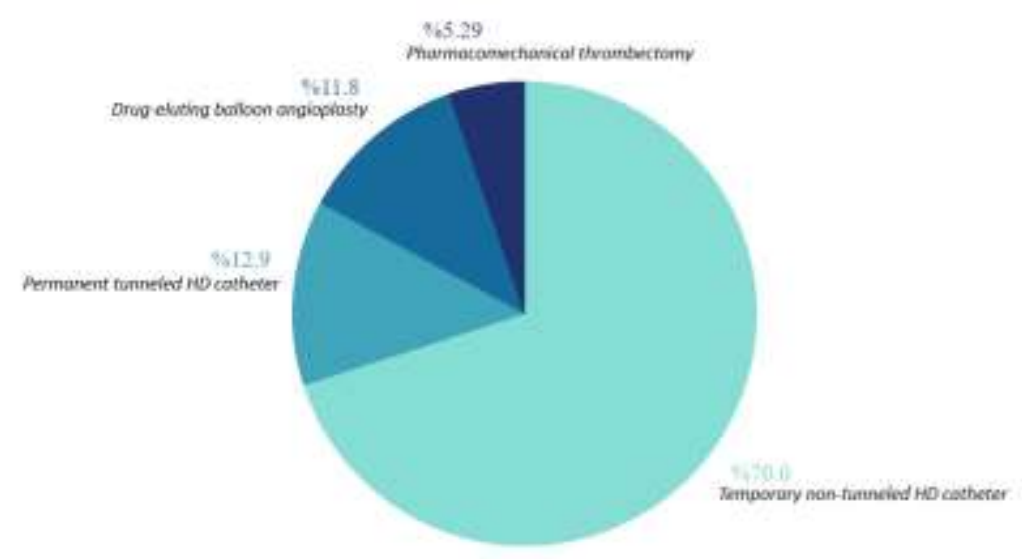

Graphic 2: Endovascular / Interventional procedural details of the patients.

\section{Discussion}

As a result of the severe COVID-19 pandemic all over the world, health care systems have been disrupted, however, it has been decided that elective surgical cases should be postponed worldwide. [9,10] Given these discussions, most vascular surgeons have reduced their practice patterns to emergency vascular surgery and very urgent cases.

In treating COVID-19 or suspected patients, it is very important to perform surgical procedures using personal protective equipment (PPE) in emergency cases. In addition, appropriate sterilization should be done between cases and patient-based protocols should be applied. [11] Procedures that can be applied to the bedside are very important in terms of preventing minimal contact and inter-patient transmission. Compared to surgeries in the operating room, interventional radiology procedures may potentially require less PPE and less support staff. [11] During the operations of COVID-19 or suspected patients, it is also recommended to use glasses, visors and double-layer gloves. [12]

As known, acute limb ischemia (ALI) is an important condition that leads to limb loss an deven death of patient if the diagnosis is delayed. [13] The rate of limb loss in ALI is about $40 \%$ with a high mortality rate ranging between 15 and 20\%. [14] In the present study, there were no limb loss in any of the patients and postoperative mortality in 4 patients in their follow-up because of COVID-19 pneumonia and older age. However, another important issue is traumatic vascular injuries. Vascular injuries constitute approximately 2-3\% of all injuries. [4] These life-threatening serious injuries can cause loss of limb function or limb loss if they are not treated timely and appropriately. [4,6]

Multisystemic organ failure associated with COVID-19 requires a multidisciplinary approach by many specialists. Among these, radiologists, neurologists, cardiovascular surgeons and cardiologists with interventional radiology experience play an important role in this field. Immune system activation due to COVID-19 causes prothrombotic conditions to occur. [15] For this reason, it is very important to diagnose DVT and start an appropriate anticoagulant regimen in patients who are hospitalized for a long time due to COVID19. However, the management of these phenomena can be very difficult and complex. PMT treatment can be considered as an important option in suitable patients with low bleeding risk, young age, no history of cancer and no history of recurrent thrombosis. [16] In patients hospitalized for severe COVID-19, acute pulmonary embolism (PE) detected by imaging methods is seen in $30 \%$ of patients. [17] Especially the management of these cases is very difficult due to coagulopathy and anti-thrombotic treatments. [18] In addition, the effectiveness of inferior vena cava (IVC) filter placement in these patients is unknown. When renal complications associated with COVID-19 were examined, $36.6 \%$ of hospitalized patients had acute kidney injury, and $14.3 \%$ of them required dialysis and renal replacement therapy. [19] In our clinic, we frequently place a temporary hemodialysis catheter from the femoral vein as bedside in patients with acute renal failure.

Although this study has some limitations including retrospective and single-center design with a relatively small sample size.

\section{Conclusion}

The present study shows how surgical and interventional procedures participated in the care of hospitalized COVID-19 patients at a tertiary care center in Yozgat City during the height of the coronavirus pandemic. In the face of this highly contagious disease, it is critical to have infection control measures, whether invasive or open procedure or not. As cardiovascular surgeons, feel comfortable doing our best in this challenging process.

\section{Declaration of Conflicting Interests}

The author(s) declared no potential conflicts of interest with respect to the research, authorship, and/or publication of this article.

\section{Funding}

The author(s) received no financial support for the research, authorship, and/or publication of this article. 


\section{REFERENCES}

1. National Institutes of Health. Coronavirus disease 19 (COVID-19). Available at: coronavirus. Accessed April 9, 2020.

2. Zaim S, Chong JH, Sankaranarayanan V, Harky A. COVID19 and multi-organ response. Curr Probl Cardiol 2020:100618.

3. Hirsch JS, Ng JH, Ross DW, Sharma P, Shah HH, Barnett $\mathrm{RL}$, et al. Acute kidney injury in patients hospitalized with COVID-19. Kidney Int 2020;98:209-218.

4. Depboylu BC, Külcü N, Yolyapan DA. Our surgical experience in peripheral vascular injuries: Retrospective analysis of 45 Cases. Turk J Vasc Surg 2015;24(1):22-28.

5. Bikdeli B, Madhavan MV, Jimenez D, Chuich T, Dreyfus I, Driggin E, et al. COVID- 19 and thrombotic or thromboembolic disease: implications for prevention, antithrombotic therapy, and follow-up. J Am Coll Cardiol 2020.

6. Halıcı Ü, Karal İH, Ağırbaş H, Kanca A. Our experiences with the surgical repair of traumatic vascular injuries. Turk J Vasc Surg 2020;29(3):145-151.

7. Lee KS, Talenfeld AD, Browne WF, Holzwanger DJ, Harnain C, Kesselman A, et al. Role of interventional radiology in the treatment of COVID-19 patients: Early experience from an epicenter. Clin Imaging. 2021 Mar;71:143-146.

8. Yiğit G, Sarıcaoğlu MC, Çetinkaya F, Özen A, İşcan HZ. Endovascular treatment of chronic total occlusion of iliac/femoral arteries: Mid-term follow-up. Turk J Vasc Surg 2020;29(1):7-12.

9. American College of Surgeons. COVID-19: recommendations for management of elective surgical procedures. Available at: elective-surgery. Accessed April 6, 2020.

10. American College of Surgeons. COVID-19 guidelines for triage of vascular surgery patients.
11. Mavioğlu HL, Ünal EU, Aşkın G, Küçüker ŞA, Özatik MA. Perioperative planning for cardiovascular operations in the COVID-19 pandemic. Turk Gogus Kalp Dama 2020;28(2):236-243.

12. Wilder-Smith A, Chiew CJ, Lee VJ. Can we contain the COVID-19 outbreak with the same measures as for SARS? Lancet Infect Dis. 2020 May;20(5):e102-e107.

13. Bozkurt AK. Akut bacak iskemisi. In: Bozkurt AK, editor. Periferik Arter ve Ven Hastalıkları. Ulusal Tedavi Kılavuzu 2016. İstanbul: Baycinar Tıbbi Yayıncıl1k; 2016. s. 44-61.

14. Norgren L, Hiatt WR, Dormandy JA, Nehler MR, Harris KA, Fowkes FG; TASC II Working Group. Inter-Society Consensus for the Management of Peripheral Arterial Disease (TASC II). J Vasc Surg 2007;45:S5-67.

15. Han H, Yang L, Liu R, Liu F, Wu KL, Li J, Liu XH, Zhu CL. Prominent changes in blood coagulation of patients with SARS-CoV-2 infection. Clin Chem Lab Med. 2020 Jun 25;58(7):1116-1120.

16. Winokur RS, Sista AK. DVT Intervention in the PostATTRACT Era. Curr Treat Options Cardiovasc Med 2018;20:70.

17. Günertem E, Akay T, Aliyev A, Beyazpınar S, Erdil N, Erer $\mathrm{D}$, et al. Treatment and prophylaxis strategies for deep vein thrombosis during COVID-19 outbreak. Turk J Vasc Surg 2020;29(3):203-207.

18. Haig Y, Enden T, Grøtta O, Kløw NE, Slagsvold CE, Ghanima W, et al. Post-thrombotic syndrome after catheterdirected thrombolysis for deep vein thrombosis (CaVenT): 5-year follow-up results of an open-label, randomised controlled trial. Lancet Haematol 2016;3:e6471.

19. Mokrzycki MH, Coco M: Management of hemodialysis patients with suspected or confirmed COVID-19 infection: perspective of two nephrologists in the United States. Kidney 360:1 (4) 273-278.
This work is licensed under Creative Commons Attribution 4.0 License

To Submit Your Article Click Here: Submit Manuscript

DOI: $10.31579 / 2641-0419 / 170$

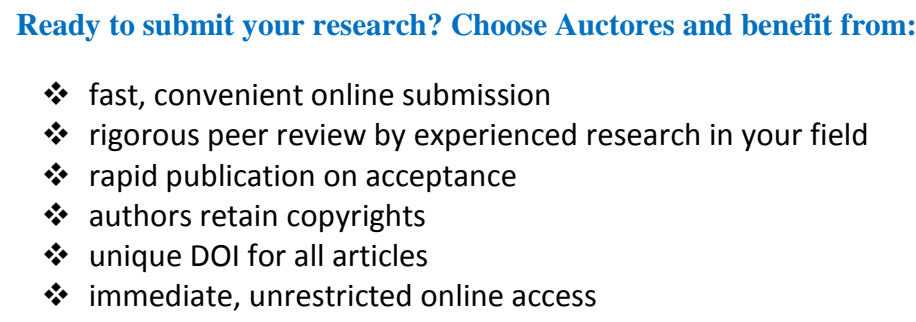

At Auctores, research is always in progress.

Learn more www.auctoresonline.org/journals/clinical-cardiology-andcardiovascular-interventions 